\title{
Protein Expression of Aryl Hydrocarbon Receptors in Human Placentas from Mild Preeclamptic and Early Pregnancies
}

\author{
Ke-hong Hao1, Qian Zhou², Qi-zhi He3, Jing Zheng4,* and Kai Wang2,* \\ ${ }^{1}$ Department of Obstetrics, Shanghai First Maternity and Infant Hospital, \\ Tongji University School of Medicine, Shanghai, \\ ${ }^{2}$ Clinical and Translational Research Center, Shanghai First Maternity \\ and Infant Hospital, Tongji University School of Medicine, Shanghai, \\ ${ }^{3}$ Department of Pathology, Shanghai First Maternity and Infant Hospital, \\ Tongji University School of Medicine, Shanghai, \\ ${ }^{4}$ Department of Obstetrics and Gynecology, Perinatal Research Laboratories, \\ University of Wisconsin, Madison, WI, \\ 1,2,3P.R. China \\ ${ }^{4}$ USA
}

\section{Introduction}

The aryl hydrocarbon receptor (AhR), a ligand-dependent transcription factor, mediates a variety of biological processes [[1]]. AhR is a classic receptor for environmental toxicants/carcinogens such as 2,3,7,8-tetrachlorodibenzo-p-dioxin (TCDD) and 3methylcholanthrene (3MC). Upon binding to these ligands, AhR could adversely affect embryonic and fetal growth as well as male and female reproduction [[1],[2]]. For instance, prenatal exposure to TCDD may cause fetotoxicity, delayed puberty, decreased sperm count, and reduced fertility [[2]]. Interestingly, AhR knockout in mice can also lead to similar adverse phenotypes in the reproductive system (e.g., impaired implantation and pregnancy) [[3]-[6]]. Thus, these data clearly indicate the physiological roles of AhR in implantation and pregnancy.

Preeclampsia is a life threatening complication of pregnancy, accounting for almost $10-15 \%$ of pregnancy-associated deaths and one of the major causes of iatrogenic prematurity among newborns [[7]]. The pathogenesis of preeclampsia is thought to act at three levels, defective placentation, placental ischemia, and endothelial cell dysfunction.

Protein expression of AhR has been identified in the placentas of many mammalian species including mouse and rabbit [[8],[9]]. Human placentas also contained high density of specific binding sites for TCDD as compared with rat and mouse livers, implying high AhR expression in human placentas [[10]]. This was confirmed by the observation that human

${ }^{*}$ Corresponding Author 
placentas had highest levels of AhR mRNA among many human organs including lung, liver, heart, brain, and kidney [[11]]. Recently, we have also reported that AhR protein is highly expressed in term human placentas, although no difference in AhR protein levels was detected between normal $(\mathrm{N})$ and severe preeclamptic (sPE) placentas [[12]]. However, the information on $\mathrm{AhR}$ protein expression in mild preeclamptic ( $\mathrm{mPE})$ and first trimester placentas was still lacking. Herein, we examined the AhR protein expression in term human placentas from women with $\mathrm{N}$ and $\mathrm{mPE}$ pregnancies as well as in first trimester placentas using immunohistochemistry and Western blotting.

\section{Materials and methods}

\subsection{Tissue collection}

Term placentas were obtained immediately after cesarean section delivery from women with $\mathrm{N}(\mathrm{n}=14)$ and $\mathrm{mPE}(\mathrm{n}=10)$ pregnancies as described [[12],[13]]. The first trimester placentas $(n=12)$ were obtained from women with induced abortion at gestation time of 6-8 weeks. Collection of placentas was approved by the Ethics Committee of Shanghai First Maternity and Infant Hospital, Tongji University School of Medicine. Written informed consent to participate in the study was obtained from each patient. Preeclampsia was defined according to the guideline of USA National Institutes of Health publication No. 003029 [[14]]. The mPE was defined as onset of hypertension during late pregnancy with systolic and diastolic blood pressure more than 140 / $90 \mathrm{mmHg}$ on at least two occasions and urinary protein more than $0.3 \mathrm{~g} / 24 \mathrm{~h}$. All of the study subjects didn't have any medication during gestation. They were free of major diseases and substance abuse. Smokers were excluded. Patients' ages were similar between $\mathrm{N}$ and $\mathrm{mPE}$ pregnancies. There was no significant difference in gestation ages and fetal weights between $\mathrm{N}$ and $\mathrm{mPE}$ pregnancies (see table 1). Placental tissues under the chorionic and basal plates were dissected ( 10 g each), snap-frozen and quickly stored in liquid nitrogen for Western blotting. Additional placental tissues from first trimester $(n=5)$ and term placentas $(n=5)$, and $\mathrm{mPE}$ placentas $(\mathrm{n}=5)$ were fixed overnight at $4^{\circ} \mathrm{C}$ using $4 \%$ paraformaldehyde in 10 $\mathrm{mM}$ PBS and embedded them in paraffin for immunohistochemistry.

\begin{tabular}{lccc}
\hline Characteristics & $\begin{array}{c}\text { Normal } \\
(\mathrm{n}=14)\end{array}$ & $\begin{array}{c}\text { Mild PE } \\
(\mathrm{n}=10)\end{array}$ & $\begin{array}{c}\text { P value } \\
(p \leq 0.05)\end{array}$ \\
\hline Patient ages (yr) & $24 \pm 1.2$ & $25 \pm 1.8$ & NS \\
Gestation ages (wk) & $39 \pm 0.2$ & $38 \pm 0.6$ & NS \\
Fetal weights $(\mathrm{g})$ & $3414 \pm 80.3$ & $2966 \pm 130.2$ & NS \\
\hline
\end{tabular}

Data are expressed as means $\pm \mathrm{SEM}, p \leq 0.05$ is considered statistically significant

Table 1. The characteristics of women from normal and mPE pregnancies.

\subsection{Immunohistochemistry}

Immunolocalization of $\mathrm{AhR}$ in placental tissues was visualized by indirect observation via the avidin:biotinylated-peroxidase complex method (Vector Laboratories, Burlingame, CA) as described [[12],[13]]. Tissue sections (5 $\mu \mathrm{m}$ thick) were deparaffinized and dehydrated, followed by incubating the sections in a $10 \mathrm{mM}$ citrate buffer solution $(\mathrm{pH} 6.0)$ in a microwave for $10 \mathrm{~min}$ for antigen retrieval. Then the tissue sections were immersed in $3 \%$ 
$\mathrm{H}_{2} \mathrm{O}_{2}$ in methanol for $10 \mathrm{~min}$ in order to quench endogenous peroxidase activity. After blocking the non-specific binding sites with $1 \%$ horse serum albumin, the sections were incubated with a rabbit AhR antibody (1:500; BIOMOL International, Plymouth Meeting, PA) for $1 \mathrm{~h}$ and a biotinylated mouse anti-rabbit antibody (ABC kit; Vector Laboratories) for $30 \mathrm{~min}$. The specific immunoreactivity was visualized by 3-amino-9-ethylcarbazole (AEC, Vector Laboratories). The tissue sections were lightly counter-stained with Harris Modified Hematoxylin (Fisher Scientific, Pittsburgh, PA). Additional adjacent tissue sections as negative controls were incubated with the same dilution of preimmune rabbit IgG as the primary antibody.

\subsection{Western blotting}

Western blotting was carried out as described [[12],[13]]. Placental tissues were pulverized in liquid nitrogen using a mortar and pestle, followed by prepared in RIPA lysis buffer (50 mM HEPES, $0.1 \mathrm{M} \mathrm{NaCl}, 10 \mathrm{mM}$ EDTA, $4 \mathrm{mM}$ sodium pyrophosphate, $10 \mathrm{mM}$ sodium fluoride, $2 \mathrm{mM}$ sodium orthovanadate [pH 7.5]; $1 \mathrm{mM}$ phenyl methyl sulfonyl fluoride [PMSF], 1\% Triton X-100, $5 \mu \mathrm{g} / \mathrm{ml}$ leupeptin, $5 \mu \mathrm{g} / \mathrm{ml}$ aprotinin), and further lyzsed by sonication. After centrifugation, the supernatant was saved and protein concentrations in supernatants were determined by BCA kit.

The protein samples $(40 \mu \mathrm{g})$ were subjected to electrophoresis on $10 \%$ SDS-PAGE gels, followed by electrically transferring to polyvinylidene difluoride membranes. The membranes were incubated with the AhR antibody (1:2000; BIOMOL) and then reprobed with a GAPDH (1:5000; KANGCHEN, Shanghai, China) antibody as a loading control. Membranes were reacted with ECL reagents (Amersham Biosciences, Piscataway, NJ). Protein bands on the membranes were visualized by exposuring them to chemiluminescence films. The immunoreactive signals were analyzed by densitometry. The optical density (OD) value was measured by the Image-J imaging analysis software (US National Institutes of Health; Bethesda, MD).

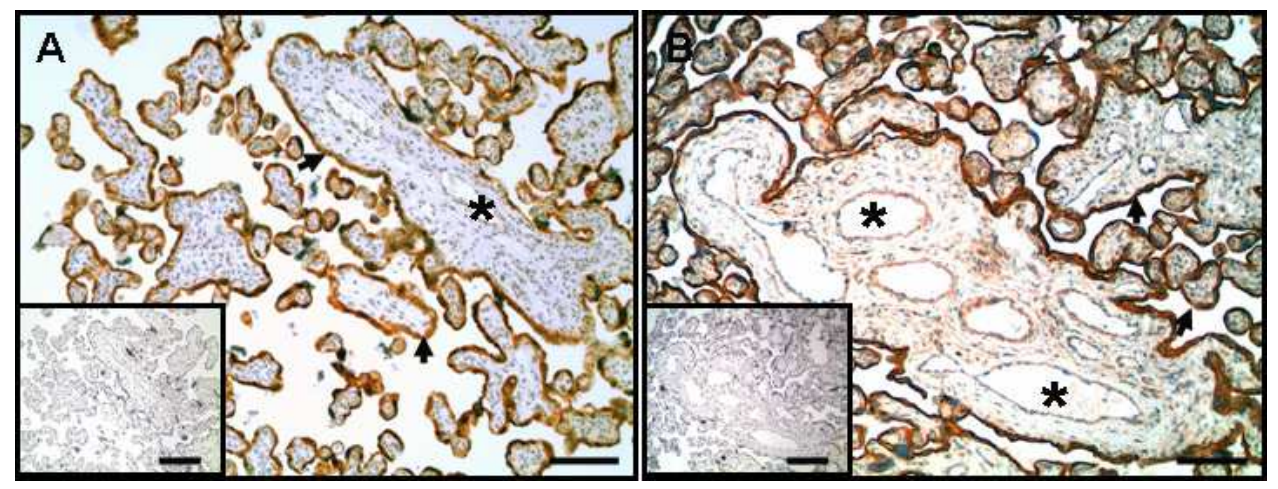

Fig. 1. Immunolocalization of AhR in human placentas from women with normal and $\mathrm{mPE}$ pregnancies. The adjacent tissues sections were incubated either with a rabbit AhR antibody $(4 \mu \mathrm{g} / \mathrm{ml})$ or preimmune rabbit IgG $(4 \mu \mathrm{g} / \mathrm{ml}$; in inserts). Reddish color indicates positive staining for AhR. Representative images from $\mathrm{N}(\mathrm{A})$ and $\mathrm{mPE}(\mathrm{B})$ pregnancies are shown. Arrows heads, syncytiotrophoblasts; asterisk, lumen of blood vessels. Bar, $100 \mu \mathrm{m}$. 


\subsection{Statistics procedures}

Data for the AhR protein levels were analyzed using the Student's t-test (SigmaStat; Jandel Co., San Rafael, CA); * $p \leq 0.05$ were considered to be statistically significant.

\section{Results}

\subsection{AhR protein localization and expression in N and mPE placentas}

Positive reddish staining for AhR was observed primarily in syncytiotrophoblasts in $\mathrm{N}$ and $\mathrm{mPE}$ placentas. There was also moderate staining in endothelial cells from large blood vessels (Fig. 1A and $1 \mathrm{~B}$ ) as described ([12]). The protein levels of $\mathrm{AhR}$ in $\mathrm{N}$ and $\mathrm{mPE}$ placentas were further determined by Western blotting (Fig. 2). The AhR band was detected at $\sim 95 \mathrm{kDa}$ (Fig. 2A) as previously reported in many species including human [[12],[15]]. The AhR protein levels in $\mathrm{mPE}$ placentas were approximately 5.6 fold higher $(p \leq 0.05)$ than those in $\mathrm{N}$ placentas (Fig. 2B).

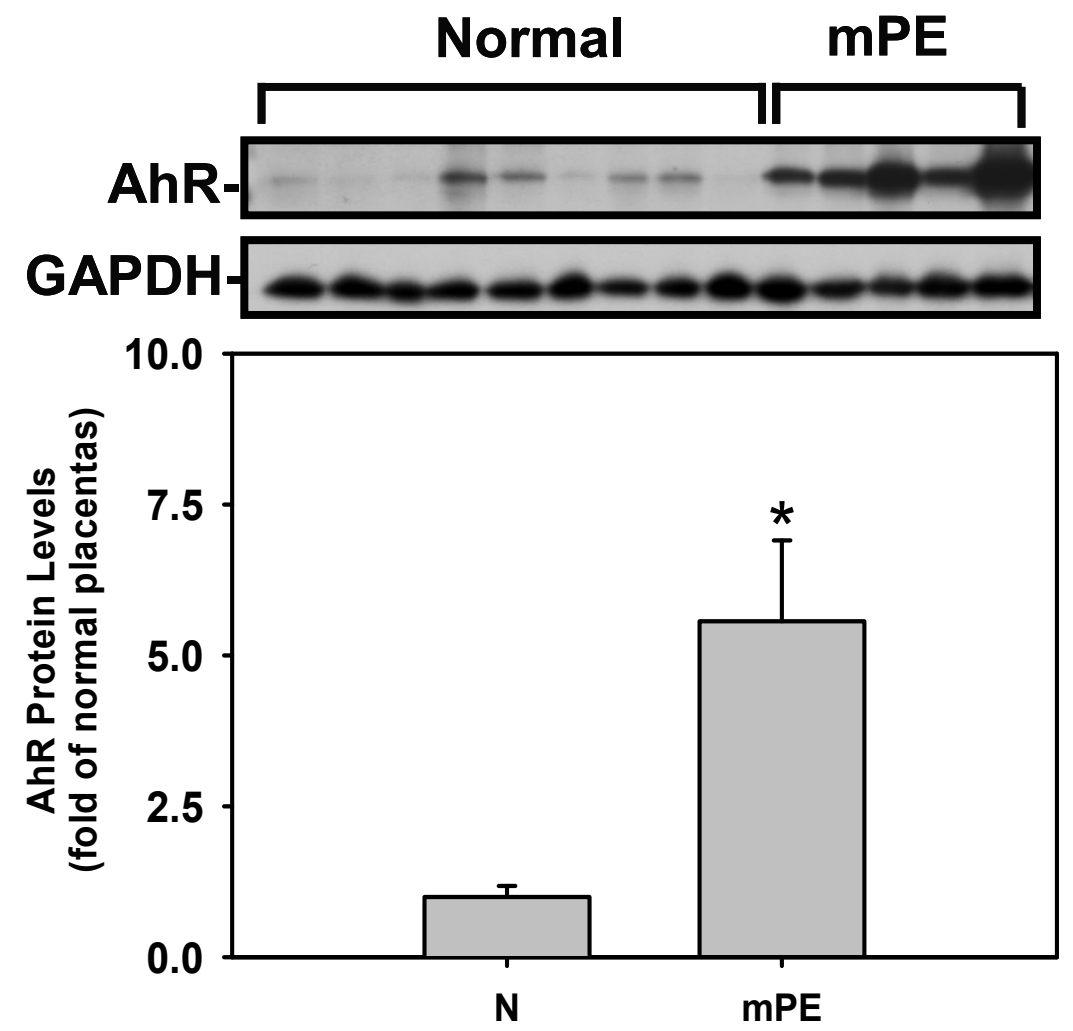

Fig. 2. Western blot analysis for AhR in human placentas from women with $\mathrm{N}$ and $\mathrm{mPE}$ pregnancies. Human placentas were obtained from $N(n=14)$ and $\mathrm{mPE}(\mathrm{n}=10)$ pregnancies. Representative Western blot images are shown for AhR and GAPDH. Data normalized to GAPDH are expressed as means \pm SEM fold of $N$ placentas. *Differs $(p \leq 0.05)$ from the $\mathrm{N}$ placentas. 


\subsection{Protein expression of $A h R$ in first trimester placentas}

Similar to term plancentas, AhR was also mainly immunolocalized in syncytiotrophoblasts in first trimester placental villi (Fig. 3A). However, in contrast to term placentas, moderate positive AhR staining was observed in capillaries within first trimester placental villi (Fig. $3 \mathrm{~B})$, suggesting the possible roles of $\mathrm{AhR}$ in mediating placental endothelial functions including angiogenesis during human early pregnancy. Western blot analysis indicated that overall AhR protein levels in term placentas were $\sim 2.2$ fold higher $(p \leq 0.05)$ than those in first trimester placentas (Fig. 4).

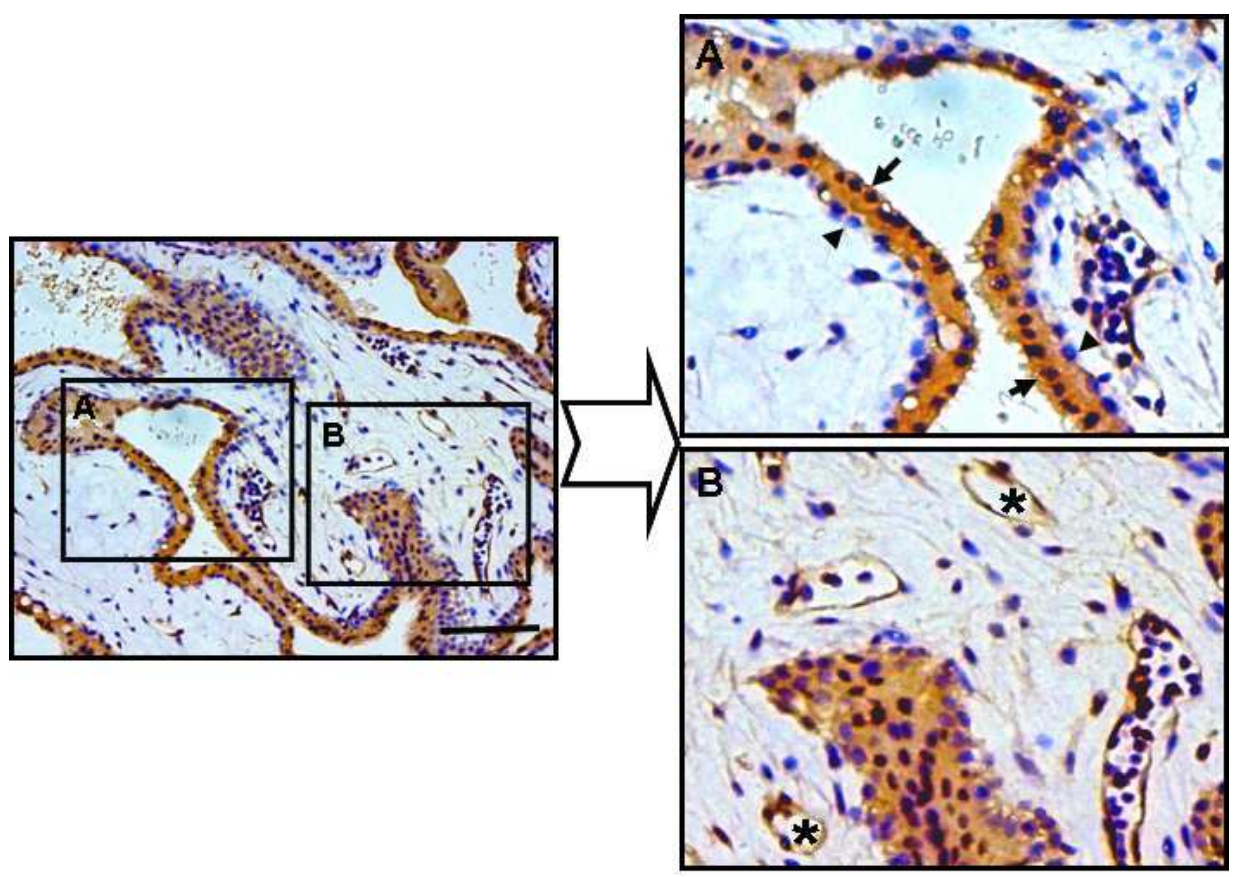

Fig. 3. Immunolocalization of AhR in human first trimester placentas. Reddish color indicates positive staining for AhR. Representative images from first-trimester placentas are shown. Arrow heads, syncytiotrophoblasts; arrows, cytotrophoblasts; asterisk, lumens of blood vessels. Bar, $100 \mu \mathrm{m}$.

\section{Disscusion}

In the current study, we have described the expression and localization of AhR protein in human term placentas from $\mathrm{N}$ and $\mathrm{mPE}$ preeclamptic pregnancies as well as in human first trimester placentas using immunohistochemistry and Western blot analyses. It is the first, as far as we know, to report that higher AhR protein levels were associated with $\mathrm{mPE}$, while much higher AhR protein levels were expressed in term placentas as compared to first trimester placentas. Another major finding of the current study was that intense AhR staining was detected primarily in syncytiotrophoblasts in both first trimester and term placentas. Interestingly, moderate AhR expression was observed in capillary endothelial 

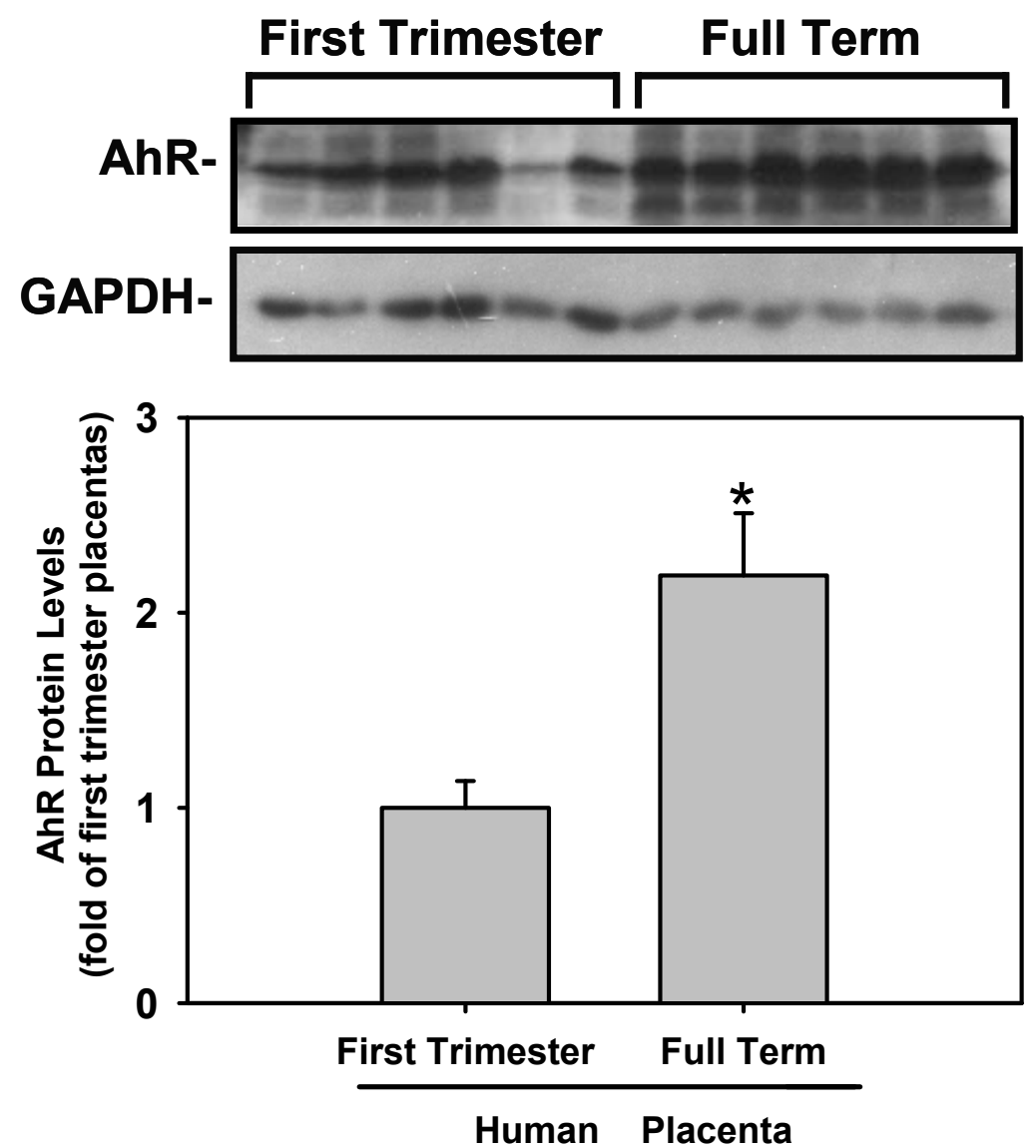

Fig. 4. Western blot analysis for AhR in human first trimester and full term placentas. First trimester $(n=12)$ placentas were obtained from women with induced abortion at 5 to 8 weeks of gestation without any complications. Representative Western blots are shown for AhR and GAPDH. Data normalized to GAPDH are expressed as means \pm SEM fold of first trimester placentas. *Differs $(p \leq 0.05)$ from first trimester placentas.

cells within villi in the first trimester, but not term placentas (the current study and [12]). These findings suggest that AhR might play a critical role in mediating syncytiotrophoblast function, particularly in $\mathrm{mPE}$ and term placentas. The distinct distribution patterns of AhR protein in different placental vasculatures (capillaries vs. large blood vessels) during early and late pregnancies also imply that AhR might differentially mediate placental endothelial functions. For example, AhR may actively mediate placental angiogenesis at early pregnancy and placental vasodilatation during late pregnancy.

The expression of AhR mRNA and protein has been reported in the placenta of many mammalians including mouse and rabbit [[8],[9]]. We have also reported the AhR protein expression in the term human placenta from $\mathrm{N}$ and $\mathrm{sPE}$ pregnancies using Western blot 
analysis [[12]]. The current study further showed the AhR protein expression in $\mathrm{MPE}$ and early pregnant placentas. Interestingly, the higher AhR protein levels were associated with $\mathrm{mPE}$, while our previous work detected similar levels of AhR protein in normal term and sPE placentas [[12]]. Although mechanisms underlying such differential AhR protein expression between $\mathrm{mPE}$ and sPE placentas remain to be elucidated, it is possible that such differences might attribute to the shorter gestation ages in $\mathrm{PPE}$ than $\mathrm{mPE}$ pregnancies since women with SPE were much more likely to suffer premature delivery. This is also in line with our present observation that placental AhR protein levels were much lower in early pregnancy than those in term pregnancy. These data also support the notion that the pathogenesis of $\mathrm{mPE}$ and $\mathrm{sPE}$ may not be completely the same as proposed previously [[15]]. Moreover, the higher protein levels of AhR could be potentially used as a marker for predicting $\mathrm{mPE}$ when in conjunction with other clinical diagnoses.

Our current observations that AhR protein was mainly present in the cytoplasm and nuclei of syncytiotrophoblasts, but not in cytotrophoblast cells in both first trimester and full term placentas were in agreement with recent findings by Stejskalova et al [[16]], suggesting that AhR might predominantly act on syncytiotrophoblasts during human pregnancy. The exact roles of $\mathrm{AhR}$ in syncytiotrophoblasts are currently unclear. However, given that syncytiotrophoblasts are terminally differentiated cells and are also responsible for producing many types of steroid and peptide hormones. It is possible that AhR might dynamically mediate syncytiotrophoblast differentiation and placental hormonal synthesis, particularly during late pregnancy, to support pregnancy and embryo/fetal development in uteri as AhR null female mice have difficulties to do so [[6],[7]]. In addition, higher AhR protein levels in term placentas than early pregnant placentas also suggest that the former might be more sensitive to AhR ligands' stimulation regardless if these ligands are derived from exogenous or endogenous sources [[17],[18]].

In conclusion, together with the recent findings of endogenous AhR ligands produced by human and animals [[17],[18]], the current data strongly support the notion that AhR plays important physiological roles in mediating normal differentiation and development of cytotrophoblast as well as placental endothelial cells to maintain successful pregnancy.

\section{Acknowledgments}

This work was supported, in part, by US NIH grants HL64703 and HD38843 (JZ), National Natural Science Foundation of China (No. 39970579, KW), and Shanghai Natural Science Foundation (No.11ZR1428700, KW)

\section{References}

[1] Hernandez-Ochoa, I., B.N. Karman, and J.A. Flaws, The role of the aryl hydrocarbon receptor in the female reproductive system. Biochem Pharmacol, 2009. 77(4): p. 54759.

[2] Peterson, R.E., H.M. Theobald, and G.L. Kimmel, Developmental and reproductive toxicity of dioxins and related compounds: cross-species comparisons. Crit Rev Toxicol, 1993. 23(3): p. 283-335. 
[3] Fernandez-Salguero, P.M., et al., Lesions of aryl-hydrocarbon receptor-deficient mice. Vet Pathol, 1997. 34(6): p. 605-14.

[4] Benedict, J.C., et al., Physiological role of the aryl hydrocarbon receptor in mouse ovary development. Toxicol Sci, 2000. 56(2): p. 382-8.

[5] Abbott, B.D., et al., Adverse reproductive outcomes in the transgenic Ah receptordeficient mouse. Toxicol Appl Pharmacol, 1999. 155(1): p. 62-70.

[6] Hernandez-Ochoa, I., et al., The ability of the aryl hydrocarbon receptor to regulate ovarian follicle growth and estradiol biosynthesis in mice depends on stage of sexual maturity. Biol Reprod, 2010. 83(5): p. 698-706.

[7] Page, N.M., The endocrinology of pre-eclampsia. Clin Endocrinol (Oxf), 2002. 57(4): p. 413-23.

[8] Kitajima, M., et al., Expression of the arylhydrocarbon receptor in the peri-implantation period of the mouse uterus and the impact of dioxin on mouse implantation. Arch Histol Cytol, 2004. 67(5): p. 465-74.

[9] Tscheudschilsuren, G., et al., Expression of the arylhydrocarbon receptor and the arylhydrocarbon receptor nuclear translocator during early gestation in the rabbit uterus. Toxicol Appl Pharmacol, 1999. 160(3): p. 231-7.

[10] Manchester, D.K., et al., Ah receptor in human placenta: stabilization by molybdate and characterization of binding of 2,3,7,8-tetrachlorodibenzo-p-dioxin, 3methylcholanthrene, and benzo(a)pyrene. Cancer Res, 1987. 47(18): p. 4861-8.

[11] Dolwick, K.M., et al., Cloning and expression of a human Ah receptor cDNA. Mol Pharmacol, 1993. 44(5): p. 911-7.

[12] Jiang, Y.Z., et al., Expression of aryl hydrocarbon receptor in human placentas and fetal tissues. J Histochem Cytochem, 2010. 58(8): p. 679-85.

[13] Chung, J.Y., et al., Differential expression of vascular endothelial growth factor (VEGF), endocrine gland derived-VEGF, and VEGF receptors in human placentas from normal and preeclamptic pregnancies. J Clin Endocrinol Metab, 2004. 89(5): p. 248490.

[14] Report of the National High Blood Pressure Education Program Working Group on High Blood Pressure in Pregnancy. Am J Obstet Gynecol, 2000. 183(1): p. S1-S22.

[15] Gregg, A.R., Hypertension in pregnancy. Obstet Gynecol Clin North Am, 2004. 31(2): p. 223-41, v.

[16] Stejskalova, L., et al., Aryl hydrocarbon receptor (AHR) and aryl hydrocarbon nuclear translocator (ARNT) expression in human and rat placentas and transcription activity in human trophoblast cultures. Toxicol Sci, 2011.

[17] Song, J., et al., A ligand for the aryl hydrocarbon receptor isolated from lung. Proc Natl Acad Sci U S A, 2002. 99(23): p. 14694-9.

[18] Nguyen, L.P. and C.A. Bradfield, The search for endogenous activators of the aryl hydrocarbon receptor. Chem Res Toxicol, 2008. 21(1): p. 102-16. 


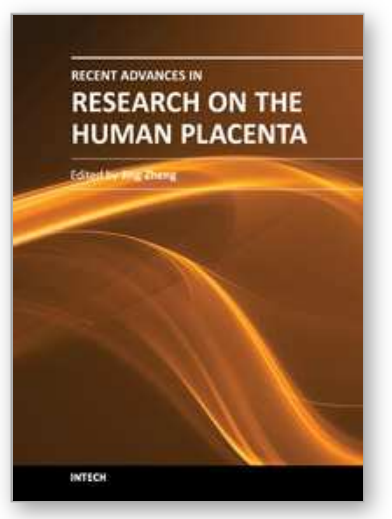

\author{
Recent Advances in Research on the Human Placenta \\ Edited by Dr. Jing Zheng
}

ISBN 978-953-51-0194-9

Hard cover, 428 pages

Publisher InTech

Published online 07, March, 2012

Published in print edition March, 2012

This book contains the total of 19 chapters, each of which is written by one or several experts in the corresponding field. The objective of this book is to provide a comprehensive and most updated overview of the human placenta, including current advances and future directions in the early detection, recognition, and management of placental abnormalities as well as the most common placental structure and functions, abnormalities, toxicology, infections, and pathologies. It also includes a highly controversial topic, therapeutic applications of the human placenta. A collection of articles presented by active investigators provides a clear update in the area of placental research for medical students, nurse practitioners, practicing clinicians, and biomedical researchers in the fields of obstetrics, pediatrics, family practice, genetics, and others who may be interested in human placentas.

\title{
How to reference
}

In order to correctly reference this scholarly work, feel free to copy and paste the following:

Ke-hong Hao, Qian Zhou, Qi-zhi He, Jing Zheng and Kai Wang (2012). Protein Expression of Aryl Hydrocarbon Receptors in Human Placentas from Mild Preeclamptic and Early Pregnancies, Recent Advances in Research on the Human Placenta, Dr. Jing Zheng (Ed.), ISBN: 978-953-51-0194-9, InTech, Available from: http://www.intechopen.com/books/recent-advances-in-research-on-the-human-placenta/protein-expression-ofaryl-hydrocarbon-receptors-in-human-placentas-from-mild-preeclamptic-and-early

\section{INTECH}

open science | open minds

\section{InTech Europe}

University Campus STeP Ri

Slavka Krautzeka 83/A

51000 Rijeka, Croatia

Phone: +385 (51) 770447

Fax: +385 (51) 686166

www.intechopen.com

\section{InTech China}

Unit 405, Office Block, Hotel Equatorial Shanghai

No.65, Yan An Road (West), Shanghai, 200040, China 中国上海市延安西路65号上海国际贵都大饭店办公楼 405 单元

Phone: +86-21-62489820

Fax: $+86-21-62489821$ 
(C) 2012 The Author(s). Licensee IntechOpen. This is an open access article distributed under the terms of the Creative Commons Attribution 3.0 License, which permits unrestricted use, distribution, and reproduction in any medium, provided the original work is properly cited. 